\title{
The Association of Childhood Asthma and Helicobacter pylori Infection in Sardinia
}

\author{
Maria Pina Dore ${ }^{1,2,},{ }^{*}$, Marco Massidda ${ }^{1}$, Gian Franco Meloni ${ }^{3}$, Sara Soro ${ }^{1}$, Giovanni Mario Pes ${ }^{1}$, \\ David Yates Graham ${ }^{2}$ \\ ${ }_{2}^{1}$ Medical Clinic, Department of Clinical and Experimental Medicine, University of Sassari, Sassari, Italy \\ ${ }_{3}^{2}$ Baylor College of Medicine, Michael E. DeBakey VA Medical Center, Houston, USA \\ ${ }^{3}$ Department of Surgical, Microsurgical and Medical Sciences, University of Sassari, Sassari, Italy \\ ${ }^{*}$ Corresponding author: Maria Pina Dore, Department of Clinical and Experimental Medicine, University of Sassari, n 8; 07100 Sassari, Italy. Tel: +39-079229886, Fax: +39-079228207, \\ E-mail: mpdore@uniss.it.
}

Received: August 13, 2013; Revised: October 8, 2013; Accepted: October 23, 2013

\begin{abstract}
Background: It has been suggested that Helicobacter pylori infection might reduce the risk of atopic conditions, such as asthma, in childhood. This risk reduction could relate to the "hygiene hypothesis" which proposes an association between childhood exposure to microbes and risk of atopy.

Objectives: To examine the association between Hp infection and childhood acquired asthma in Sardinia.

Patients and Methods: Children from Northern Sardinia who were between the ages of 10 months to 6 years and were screened for Hp infection in 1994-1995 using IgG serology, were asked in 2012, whether they had developed asthma and/or allergic disease in pediatric age, using the global initiative on asthma guidelines questionnaire.

Results: A total of 64 children participated in the study. The sero-positivity for Hp infection was 14.1\%. Eleven (17.2\%) children had a confirmed diagnosis of asthma with onset before the age of 5 years, $85.9 \%$ were Hp negative and $14.1 \% \mathrm{Hp}$ positive. Eight children of the 53 without asthma were Hp positive (15\%) compare to one children positive for the infection of the 11 patients $(0.09 \%)$ with asthma (8/53 vs. $1 / 11 ; \mathrm{P}=0.6)$. The majority of children (73\%) were from urban areas and $43.8 \% \mathrm{had}$ a family history of asthma or allergies. Multiple logistic regression analysis was not able to find a studied variable, including Hp infection, significantly associated with pediatric asthma.

Conclusions: Our results speak against Hp infection itself playing a role to protect from the risk to develop childhood asthma although household hygiene was not directly assessed.
\end{abstract}

Keywords: Child; Asthma; Helicobacter pylori

\section{Background}

Helicobacter pylori (H. pylori) is one of the most common chronic bacterial infections of mankind affecting approximately $50 \%$ of the world's population (1). The risk of acquiring $H$. pylori infection is related to socioeconomic status and living conditions early in life and is inversely related to household hygiene practices $(1,2)$. Once acquired, the bacterium becomes the dominant member of the gastric microbiota (3).

Asthma is the most common chronic disease in childhood in developed countries $(4,5)$. In Western nations, the rate of acquisition of $H$. pylori has declined whereas the incidence of childhood asthma has increased. For example, in the USA the prevalence of childhood asthma increased more than 50\% between the 1980's and 1990's and by about $10 \%$ in the last decade (6). One hypothesis to explain this phenomenon is the so called "hygiene hypothesis" which links a reduced exposure to microbes in childhood with the increased incidence of atopy (7).
This link is postulated to relate to the alterations in the balance between a Th1 and Th2 response to antigenic stimuli. Chen and Blaser (8) suggested that the inverse relationship between the increase in atopic diseases and fall in acquisition of $H$. pylori infections might be causal (i.e. H. pylori might occupy a metabolically active compartment in the stomach involved in the immunological barrier process that protects against allergic diseases). Alternately, $H$. pylori infection could be a surrogate marker for the level of household hygiene (i.e. general exposure to microbes).

\section{Objectives}

In this study we examined the association between $H$. pylori and childhood asthma in a cohort of children from Northern Sardinia.

\section{Patients and Methods}

Children from Northern Sardinia who were between the

Implication for health policy makers/practice/research/medical education:

It has been suggested that the inverse relationship between the increase in atopic diseases and fall in acquisition of $H$. pylori infections might be causal. Our study did not confirm any protective role for H. pylori infection in childhood asthma.

Copyright (c) 2014, Pediatric Infections Research Center. This is an open-access article distributed under the terms of the Creative Commons Attribution-NonCommercial 4.0 International License (http://creativecommons.org/licenses/by-nc/4.0/) which permits copy and redistribute the material just in noncommercial usages, provided the original work is properly cited. 
ages of 10 months to 6 years were screened for $H$. pylori infection in 1994 and 1995 using H. pylori IgG serology (9). A sample of venous blood was obtained from each child participating in the study in a clinical setting. The sample was a sample of convenience obtained by follow-up of a large cohort originally selected for a study of the prevalence and epidemiology of $H$. pylori infection among Sardinian children.

Serum was separated and frozen at $-20^{\circ} \mathrm{C}$ until assay. The presence of IgG antibodies to the high molecular weight cell-associated proteins of $H$. pylori was measured using an enzyme-linked immunosorbent assay ELISA (HM-CAP, EPI, Westbury, NY). The specificity and positive predictive value of the HM-CAP ELISA were each previously shown to be $100 \%$; the sensitivity is $98.7 \%$, and the negative predictive value is $98.6 \%$. There is no cross-reactivity with Campylobacterjejuni. The test has been validated in a pediatric context (10), and from the same geographic area (northern Sardinia) (9). H. pylori infection was defined as a positive ELISA result. Antibody titer above the cut-off value of 2.2 was considered positive.
The children were reinterviewed by telephone, using a validated questionnaire [the global initiative on asthma (GINA)] (11), whether they had developed asthma and/or allergic disease in pediatric age, in 2012. Only a definite diagnosis of asthma made by the pediatrician on the base of a careful process of history taking, physical examination, and eventually diagnostic studies using spirometry and the response to treatment according to GINA criteria was considered valid (11). The questionnaire was completed by the investigators with the cooperation of the parents of each child. Information obtained included the age and sex of the child, place of residence, occupation of the head of household, and exposure to animals (dogs and other animals, e.g. cats, parrots, pigs, goats, horses, ducks, donkeys, and chickens). Whether the child had a history of breast-feeding and the family history for respiratory diseases was also recorded. The socioeconomic status of the children was based on the occupation of the head of the household and recorded in 4 subgroups as follow: major professionals (persons who had graduated from university); minor professionals and administra-

Table 1. Study Variable Analyzed by Descriptive Statistics for Children With Asthma and Without Asthma

\begin{tabular}{|c|c|c|}
\hline & \multicolumn{2}{|c|}{ Children } \\
\hline & With Asthma, No. (\%) & Without Asthma, No. (\%) \\
\hline & $11(17.2)$ & $53(82.8)$ \\
\hline \multicolumn{3}{|l|}{ H.pylori } \\
\hline Positive & $1(9.1)$ & $8(15.1 \%)$ \\
\hline Negative & $10(90.9)$ & $45(84.9)$ \\
\hline \multicolumn{3}{|l|}{ Gender } \\
\hline Male & $10(90.9)$ & $29(54.7)$ \\
\hline Female & $1(9.1)$ & $24(45.3)^{\mathrm{a}}$ \\
\hline \multicolumn{3}{|c|}{ Contact with animals } \\
\hline Yes & $2(18.2)$ & $18(34.0)$ \\
\hline No & $9(81.8)$ & $35(66.0)$ \\
\hline \multicolumn{3}{|c|}{ Family history of asthma } \\
\hline Yes & $7(63.6)$ & $21(39.6)$ \\
\hline No & $4(36)$ & $32(60.4)$ \\
\hline \multicolumn{3}{|l|}{ Residence } \\
\hline Urban & $7(63.6)$ & $36(67.9)$ \\
\hline Rural & $4(36)$ & $17(32.1)$ \\
\hline \multicolumn{3}{|c|}{ Socioeconomic Status } \\
\hline High & $7(63.6)$ & $36(67.9)$ \\
\hline Low & $4(36)$ & $17(32.1)$ \\
\hline \multicolumn{3}{|c|}{ Day care attendance } \\
\hline Yes & $7(63.6)$ & $42(79.2)$ \\
\hline No & $4(36)$ & $11(20.8)$ \\
\hline
\end{tabular}

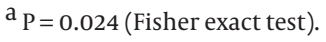


tors (persons who had not graduated from university); clerks and sales technicians; and semiskilled and unskilled workers, uneducated farmers, and shepherds. The results were assessed by a physician, and unclear answers were clarified by interviewing parents again.

Informed consent was obtained from children's parents for participation in the study, and the study protocol was approved by the Ethics Committee of the Faculty of Medicine at the University of Sassari (Sassari, Italy).

\subsection{Statistical Analysis}

Multiple logistic regression analysis, using the SPSS Enter procedure (SPSS statistical software, v. 16.0, Chicago, USA) was used to test the association between covariates and the probability to develop asthma. Odds ratios (ORs) and their 95\% confidence interval (CI) were calculated as the relative amount of increase of odds from one-unit change in the independent variables, after controlling for the confounding effect of all covariates. For purpose analysis socioeconomic status was further categorized into "low" and "high" socioeconomic status. The residence variable was coded into a binary scoring system by giving "1" or " 2 " for urban or rural setting, respectively. The P lower than 0.05 was considered statistically significant.

\section{Results}

A total of 64 children (39 boys, 29 girls) from the original population of 150 (43\%) participated in the study. Results are showed in Table 1 . Eleven (17.2\%) children had a confirmed diagnosis of asthma with onset before 5 years of age. Eight children of the 53 without asthma were $H$. pylori positive compare to one children positive for the infection of the 11 patients with asthma (8/53 vs. 1/11; $\mathrm{P}=$ 0.6 ), thus, not supporting the hypothesis of a "protective role" of $H$. pylori infection against asthma in children. Curiously this child was the only one who received breast- feeding. There were no significant associations observed between childhood asthma and the occupation of the head of the household. The history for contact with dogs was positive in only two children.

Multiple logistic regression analysis is reported in Table 2 . There were no variables, including $H$. pylori infection, significantly associated with asthma. The covariate that influences mostly the OR was the female gender, although not significantly. Besides, the effect of gender was confirmed by the contingency analysis (male 10 and 1 female with asthma vs. male 29 and female 24 without asthma; $\mathrm{P}=0.025)$. The negative number in the residence variable is associated to a greater risk to develop asthma for urban children.

\section{Discussion}

Our observations are consistent with the results of a recent meta-analysis by Wang et al. which showed that there was only a weak evidence for an inverse association between asthma and $H$. pylori infection (12). More specifically the Authors found a weak inverse association between $H$. pylori and asthma in cross-sectional studies with an OR of 0.84 and of 0.82 in the cohort studies. There were no significant inverse association between $H$. pylori and asthma in both case-control studies. In addition, stratifying by age in children and adults, significant inverse association between $H$. pylori and childhood asthma was not still observed by performing a quantitative meta-analysis (12). However there are studies reporting an inverse association between $H$. pylori infection and asthma in children under 10 years (8). Chen and Blaser in their cross-sectional analyses conducted using data from 7412 children, showed that $H$. pylori seropositivity was inversely associated with asthma in pediatric age, and the inverse association with onset of asthma before 5 years of age was stronger (OR : 0.58). H. pylori seropositivity also was inversely related to the recent onset of atopic disease (8). In a different study the same authors found that colo-

\begin{tabular}{|c|c|c|c|c|c|}
\hline Covariates & Beta $^{\mathrm{a}}$ & $\mathbf{S E}^{\mathrm{a}}$ & Significance & $\mathbf{O R}^{\mathrm{a}}$ & 95\% $\mathrm{CI}^{\mathrm{a}}$ for OR \\
\hline H.pylori & -0.494 & 2.824 & 0.861 & 0.610 & $(0.002-154.609)$ \\
\hline Gender & -1.851 & 1.113 & 0.086 & 0.157 & $(0.018-1.392)$ \\
\hline Breast Feeding & -1.020 & 0.830 & 0.219 & 0.360 & $(0.071-1.834)$ \\
\hline Animals & -0.558 & 0.935 & 0.551 & 0.573 & $(0.092-3.579)$ \\
\hline Family history of asthma & -0.874 & 0.765 & 0.253 & 0.417 & $(0.093-1.867)$ \\
\hline Residence & -0.368 & 0.792 & 0.643 & 0.692 & $(0.147-3.270)$ \\
\hline Day care attendance & 0.859 & 1.095 & 0.535 & 1.971 & $(0.231-16.846)$ \\
\hline Socioeconomic Status & 1.248 & 1.035 & 0.246 & 3.483 & $(0.424-28.642)$ \\
\hline Constant & 1.781 & 2.067 & 0.742 & 5.936 & \\
\hline
\end{tabular}

\footnotetext{
${ }^{\mathrm{a}}$ Abbreviations: Beta, regression coeficent; SE, standard error; OR, odd ratio; CI, confidence interval.
} 
nization especially with $H$. pylori CagA positive strain was inversely associated with currently or ever having a diagnosis of allergic rhinitis, especially for childhood onset (OR: 0.55) (13).

In Jeddah, Saudi Arabia, 1432 children; were tested for H. pylori status by ELISA using IgG antibodies (HM-CAP; Enteric Products Incorporation, Westbury, NY). The prevalence did not differ according to nationality and gender but significantly increased with age in children with chronic asthma, chronic anemia and neurological impairment ( $\mathrm{P}<0.01$ for all), length of illness, number of blood transfusions, number of hospital admission and type of feeding (14).

The issue regarding whether $H$. pylori infection itself vs. $H$. pylori infection acting as a surrogate marker for poor household hygiene has been tested in terms of assessing the prevalence of childhood asthma in an area where hygiene was poor but $H$. pylori infections were rare $(15,16)$. Such populations exist in Malaysia and Zanzibar and provide sites where the effects of hygiene and $H$. pylori can be separated (15-17). Studies in Malaysia have failed to confirm that any of the proposed dire consequences associated with the falling prevalence of $H$. pylori including an increase in childhood asthma, gastroesophageal reflux disease, or adenocarcinoma of the esophagus (15-17). If anything, the available studies in Malaysia cast doubt on any direct role for any protective role of $H$. pylori infection and are consistent with the hypothesis that the $H$. pylori infection instead represents a surrogate maker for poor household hygiene (18-21). The weakness of the current study is the fact that only a small cohort of children was investigated. The strength is that a follow-up was after seventeen years.

Conclusions: Our study did not confirm an association between lack of $H$. pylori infection and childhood asthma. However, we did not assess household hygiene directly but our results speak against the infection itself playing a role to protect from the risk to develop childhood asthma. The numbers of children from rural areas were also too small for us to examine whether the hygiene hypothesis itself was related to childhood asthma in this population. Prospective studies in Zanzibar and/or Malaysia are needed to be able to test whether the role of the hygiene hypothesis and whether $H$. pylori is involved, a surrogate marker of poor hygiene, or neither.

\section{Acknowledgements}

There are no acknowledgements.

\section{Authors' Contribution}

Study concept and design: David Y Graham and Maria P Dore. Data collection: Marco Massidda, Gian Franco Meloni, Sara Soro. Statistical analysis: Giovanni M Pes. Analysis and data interpretation: David Y Graham and Maria
P Dore. Manuscript drafting: Maria P Dore and Gianni M Pes. Critical revision of the manuscript: David Y Graham.

\section{Financial Disclosure}

No relevant financial interests or financial conflicts within the past 5 years and for the foreseeable future.

\section{Funding/Support}

This work was supported by Medical Clinic, Department of Clinical and Experimental Medicine.

\section{References}

1. Nurgalieva ZZ, Malaty HM, Graham DY, Almuchambetova R, Machmudova A, Kapsultanova D, et al. Helicobacter pylori infection in Kazakhstan: effect of water source and household hygiene. Am J Trop Med Hyg. 2002;67(2):201-6.

2. Nouraie M, Latifi-Navid S, Rezvan H, Radmard AR, Maghsudlu M, Zaer-Rezaii $\mathrm{H}$, et al. Childhood hygienic practice and family education status determine the prevalence of Helicobacter pylori infection in Iran. Helicobacter. 2009;14(1):40-6.

3. Bik EM, Eckburg PB, Gill SR, Nelson KE, Purdom EA, Francois F, et al. Molecular analysis of the bacterial microbiota in the human stomach. Proc Natl Acad Sci U S A. 2006;103(3):732-7.

4. Bisgaard H, Szefler S. Prevalence of asthma-like symptoms in young children. Pediatr Pulmonol. 2007;42(8):723-8.

5. Chavoshzadeh Z, Abdinia B, Fahimzad A, Samakosh H, Khanbabaei G, Tabatabaei SA. Molecular study of respiratory syncytial virus, human rhinovirus and human metapneumovirus, detected in children with acute wheezing. Arch Pediatr Infect Dis. 2012;1(1):14-7.

6. Mannino DM, Homa DM, Akinbami LJ, Moorman JE, Gwynn C, Redd SC. Surveillance for asthma--United States, 1980-1999. MMWR Surveill Summ. 2002;51(1):1-13.

7. Warner JO. The hygiene hypothesis. Pediatr Allergy Immunol 2003;14(3):145-6.

8. Chen Y, Blaser MJ. Helicobacter pylori colonization is inversely associated with childhood asthma. J Infect Dis. 2008;198(4):553-60.

9. Dore MP, Bilotta M, Malaty HM, Pacifico A, Maioli M, Graham DY et al. Diabetes mellitus and Helicobacter pylori infection. Nutrition. 2000;16(6):407-10.

10. Chong SK, Lou Q, Asnicar MA, Zimmerman SE, Croffie JM, Lee CH et al. Helicobacter pylori infection in recurrent abdominal pain in childhood: comparison of diagnostic tests and therapy. Pediatrics. 1995;96(2 Pt 1):211-5.

11. Global Initiative for Asthma. 2012. Available from: http:/ginasthma.org.

12. Wang Q, Yu C, Sun Y. The association between asthma and Helicobacter pylori: a meta-analysis. Helicobacter. 2013;18(1):41-53.

13. Chen Y, Blaser MJ. Inverse associations of Helicobacter pylori with asthma and allergy. Arch Intern Med. 2007;167(8):821-7.

14. Jaber SM. Helicobacter pylori seropositivity in children with chronic disease in Jeddah, Saudi Arabia. Saudi J Gastroenterol. 2006;12(1):21-6.

15. Farag TH, Stoltzfus RJ, Khalfan SS, Tielsch JM.Unexpectedly low prevalence of Helicobacter pylori infection among pregnant women on Pemba Island,Zanzibar.Trans R Soc Trop Med Hyg. 2007;101(9):915-22.

16. Uyub AM, Raj SM, Visvanathan R, Nazim M, Aiyar S, Anuar AK, et al. Helicobacter pylori infection in north-eastern peninsular Malaysia. Evidence for an unusually low prevalence. Scand J Gastroenterol. 1994;29(3):209-13.

17. Graham DY, Yamaoka Y, Malaty HM. Thoughts about populations with unexpected low prevalences of Helicobacter pylori infection. Trans R Soc Trop Med Hyg. 2007;101(9):849-51.

18. Graham DY, Yamaoka Y, Malaty HM. Contemplating the future without Helicobacter pylori and the dire consequences hypothesis. Helicobacter. 2007;12 Suppl 2:64-8. 


\section{Dore MP et al.}

19. Raj SM, Choo KE, Noorizan AM, Lee YY, Graham DY. Evidence against Helicobacter pylori Being Related to Childhood Asthma. J Infect Dis. 2009;199(6):914-5.

20. Holster IL, Vila AM, Caudri D, den Hoed CM, Perez-Perez GI, Blaser MJ, et al. The impact of Helicobacter pylori on atopic disorders in childhood. Helicobacter. 2012;17(3):232-7.

21. Imamura S, Sugimoto M, Kanemasa K, Sumida Y, Okanoue T, Yoshikawa T, et al. Inverse association between Helicobacter pylori infection and allergic rhinitis in young Japanese. J Gastroenterol Hepatol. 2010;25(7):1244-9. 